\title{
Microporosity Development of Herringbone Carbon Nanofibers by RbOH Chemical Activation
}

\author{
Vicente Jiménez, ${ }^{1}$ Paula Sánchez, ${ }^{1}$ Fernando Dorado, ${ }^{1}$ José Luís Valverde, ${ }^{1}$ \\ and Amaya Romero ${ }^{1,2}$ \\ ${ }^{1}$ Departamento de Ingeniería Química, Facultad de Ciencias Químicas, Universidad de Castilla-La Mancha, \\ 13071 Ciudad Real, Spain \\ ${ }^{2}$ Departamento de Ingeniería Química, Escuela Técnica Agrícola, Universidad de Castilla-La Mancha, 13071 Ciudad Real, Spain
}

Correspondence should be addressed to Amaya Romero, amaya.romero@uclm.es

Received 22 May 2009; Accepted 8 July 2009

Recommended by Valery N. Khabashesku

The influence of different activation conditions, including activating agent/CNFs ratio, activation temperature, and He flow rate, on the pore structure development of herringbone carbon nanofibers (CNFs) was studied. The best results of activated CNFs with larger specific surface area can be achieved using the following optimized factors: $\mathrm{RbOH} / \mathrm{CNF}$ ratio $=4 / 1$, activation temperature $=900^{\circ} \mathrm{C}$, and a He flow rate $=850 \mathrm{ml} / \mathrm{min}$. The optimization of these three factors leads to high CNFs micropore volume, being the surface area increased by a factor of 3 compared to the raw CNFs. It is important to note that only the creation of micropores (ultramicropores principally) took place, and mesopores were not generated if compared with raw CNFs.

Copyright (C) 2009 Vicente Jiménez et al. This is an open access article distributed under the Creative Commons Attribution License, which permits unrestricted use, distribution, and reproduction in any medium, provided the original work is properly cited.

\section{Introduction}

Carbon nanofibers (CNFs) are one of the most promising materials for many applications such as catalytic support [1], polymer reinforcement agents [2], fuel cell electrodes [3], adsorbents [4], and hydrogen storage [5]. In many cases, the problem associated to these structures is that their specific surface area is not very high (typical value around 150$200 \mathrm{~m}^{2} / \mathrm{g}$ ), which hinders many applications such as those regarding gas and energy storage. In this regard, chemical activation has been shown as a very efficient method to obtain carbons with high surface area and narrow micropore size distribution.

Although a large variety of carbon precursors have been activated by alkaline hydroxides [6] (coals, polymers, lignocelullosic, etc.), a very limited number of studies found in the literature discuss the activation of CNFs by hydroxides [7]. Moreover, it is also very important to investigate the influence of different activation conditions on the final porous texture of these materials [8]. In previous works $[9,10]$, we studied the influence of the metallic cation in the hydroxide form and the type of gas used as protector ( $\mathrm{He}, \mathrm{Ar}$, or $\mathrm{N}_{2}$ ) during the process. Thus, we could demonstrate that $\mathrm{He}$ is the best protector gas and $\mathrm{KOH}$ and $\mathrm{RbOH}$ the best activating agents.

In this work, we study the influence of the most important operation conditions in the pore development of carbon nanofibers using $\mathrm{RbOH}$ as the activating agent as an alternative to $\mathrm{KOH}$ (most frequently reactive used in chemical activation processes). The following operation conditions were studied: $\mathrm{RbOH} / \mathrm{CNF}$ ratio, activation temperature, and helium flow rate. To evaluate the structural changes in the activated CNFs, different characterization techniques were used $\left(\mathrm{N}_{2}\right.$ adsorption-desorption, $\mathrm{XRD}$, and elemental composition). The optimal values of the different variables were selected taking into account the maximum pore development according to the surface area values.

\section{Experimental}

Herringbone CNFs were grown at atmospheric pressure in a fixed-bed reactor located in a vertical oven at a temperature of $600^{\circ} \mathrm{C}$ according to the procedure described in $[9,10]$. 
After that, CNFs were activated in an experimental setup consisting on a horizontal quartz reactor tube with a conventional horizontal furnace. Thus, the appropriate amount of CNFs was mixed with $\mathrm{RbOH}$ and distilled water $(10 \mathrm{~mL}$ water for $2 \mathrm{~g} \mathrm{RbOH})$ and heated at $85^{\circ} \mathrm{C}$ for 4 hours under stirring and then dried for 12 hours at $110^{\circ} \mathrm{C}$. Finally, the mixture was placed on a ceramic crucible located inside the horizontal reactor tube. The heat treatment consisted of a heating ramp from ambient temperature to the final heat treatment temperature at a heating rate of $5^{\circ} \mathrm{C} / \mathrm{min}$, followed by a 3 -hours plateau under a determinate $\mathrm{He}$ flow rate. Later, the system was cooling back to the initial temperature. The activated product was firstly washed with hydrochloric acid $(5 \mathrm{M})$ to remove the activating agent and finally, with distilled water until a neutral washing was obtained. The resulting material was dried for 12 hours at $110^{\circ} \mathrm{C}$ in air to remove water prior to characterization.

Powder X-ray diffractograms (XRDs) were recorded with a Philips PW 1710 instrument using Ni-filtered $\mathrm{Cu}$ $\mathrm{K} \alpha$ radiation. Surface area/porosity measurements were conducted using a Micromeritics ASAP 2010 sorptometer apparatus with $\mathrm{N}_{2}$ as sorbate at $77 \mathrm{~K}$. Samples were outgased (at $6.6 \times 10^{-9}$ bar) at $180^{\circ} \mathrm{C}$ overnight prior to analysis. Specific surface areas were determined by the multipoint BET method, pore volume and size distributions were evaluated using the standard $\mathrm{BJH}$ treatment, and micropore size distributions were evaluated using the Horvath-Kawazoe $(\mathrm{H}-$ $\mathrm{K})$ equation. The carbon and hydrogen content in the solid carbon deposits was determined using a LECO CHNS-932 apparatus.

\section{Results and Discussion}

The reaction conditions that have been studied in detail are summarized in Table 1. All these parameters have an important effect on the final pore characteristics of the activated CNFs. Also in Table 1 are showen the textural properties, the elemental composition, and npg values of the activated materials.

BET surface area was, in all the cases, significantly larger than that of the parent CNFs showing the important effect that the treatment has on the porosity of carbon nanostructures. It can be seen that both the BET surface area and the micropore volume increased continuously with the $\mathrm{RbOH} / \mathrm{CNF}$ ratio, reaching a maximum for a value of $4 / 1$. At higher values (5/1), the microporosity did not increase anymore. It can also be observed in Figure 1 in which the $\mathrm{N}_{2}$ isotherms are showed. All the isotherms correspond to a mixture of I-IV type according to the IUPAC classification associated with both micropores and mesopores with a hysteresis loop resulting from capillary condensation in the mesopores. As can be seen in the isotherms, a gradual increase in the absorbed $\mathrm{N}_{2}$ with the $\mathrm{RbOH} / \mathrm{CNF}$ ratio took place until that a $4 / 1$ value was reached, indicating a higher activation degree.

On the other hand, total BET and micropore surface area increased with the activation temperature in all the

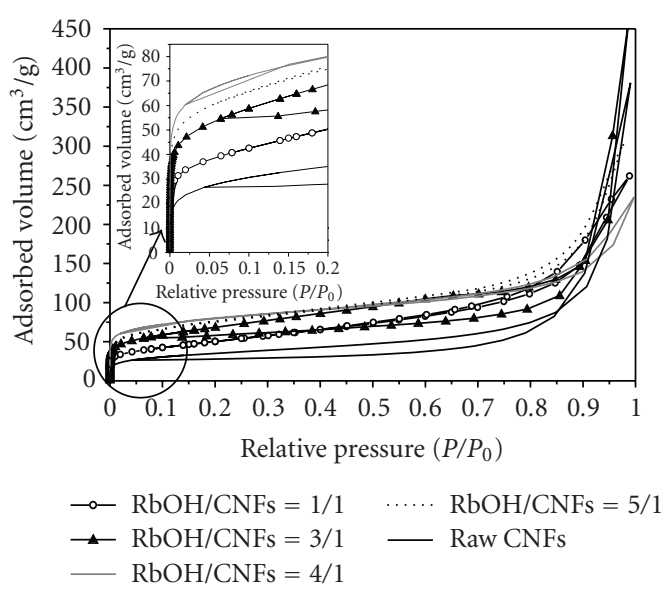

FIGURE 1: $\mathrm{N}_{2}$ adsorption-desorption isotherms as a function of the $\mathrm{RbOH} / \mathrm{CNF}$ ratio.

temperature range studied. Note that, while the micropore volume increased, the mesopore volume continuously decreased until $850^{\circ} \mathrm{C}$, but it increased at higher temperatures $\left(850-900^{\circ} \mathrm{C}\right)$. These results can be clearly observed in Figure 2 where the micropore and mesopore size distribution are showed. The population of micropores was enhanced with the temperature increase until $850^{\circ} \mathrm{C}$ in contrast with that observed for the mesopores which significantly decreased.

Finally, higher He flow rates favored the microporosity development until that a value of $850 \mathrm{~mL} / \mathrm{min}$ was reached. Later, with a further increase in the He flow rate, the porosity development (including both micro-and mesopores) started to be lower.

It is also important to note that the mesoporosity was not development at all if compared with that associated to raw CNFs concluding that $\mathrm{RbOH}$ activation was more effective in the microporosity development.

The proportions of ultramicropores, supermicropores and mesopores in the activated samples are shown in Figure 3. It can be seen that an increase in the amount of $\mathrm{RbOH}$ in the activation process produced a rise in the ultramicropore volume (coincident with the BET surface area increase) of the activated materials, reaching a maximum when the $\mathrm{RbOH} / \mathrm{CNF}$ s ratio reached a value of $4 / 1$ (Figure 3(a)). Moreover, some supermicropores were also generated. The total mesopore volume decrease that took place in activated materials compared to the raw one is the results of the strong interaction of the initial mesopores (inherent to raw CNFs) with the chemical agent responsible to the activation $(\mathrm{Rb})$ generating new micropores [11]. Note that in all the cases, the percentage of mesoporosity inherent to the parent CNFs was decreased during the activation process due to the high amount of ultramicropores created.

In a similar way, the amount ultramicropores increased with the activation temperature until $850^{\circ} \mathrm{C}$. Later, a small increase in the temperature $\left(900^{\circ} \mathrm{C}\right)$, produced the generation of new supermicropores and mesopores in expense to some ultramicropores destruction. 
TABLE 1: Textural properties and other characterization parameters of parent and activated CNFs using RbOH as the activating agent.

\begin{tabular}{|c|c|c|c|c|c|c|c|c|c|c|c|c|}
\hline $\begin{array}{l}\mathrm{RbOH} / \mathrm{CNFs} \\
\text { ratio }(\mathrm{w} / \mathrm{w})\end{array}$ & $\mathrm{T}^{\mathrm{a}}\left({ }^{\circ} \mathrm{C}\right)$ & $\begin{array}{l}\text { He flow } \\
\text { rate } \\
(\mathrm{mL} / \mathrm{min})\end{array}$ & $\begin{array}{l}\text { Carbon } \\
\text { yield (\%) }\end{array}$ & $\begin{array}{l}\text { BET } \\
\text { surface } \\
\text { Area } \\
\left(\mathrm{m}^{2} / \mathrm{g}\right) \\
\end{array}$ & $\begin{array}{l}\text { Micropore } \\
\text { area } \\
\left(\mathrm{m}^{2} / \mathrm{g}\right)^{(1)}\end{array}$ & $\begin{array}{l}\text { Micropore } \\
\text { volume } \\
\left(\mathrm{cm}^{3} / \mathrm{g}\right)^{(2)}\end{array}$ & $\begin{array}{l}\text { Mesopore } \\
\text { volume } \\
\left(\mathrm{cm}^{3} / \mathrm{g}\right)^{(3)}\end{array}$ & $\mathrm{Npg}^{(4)}$ & $\mathrm{C}$ & $\mathrm{H}$ & $\mathrm{O}_{\text {diff }}^{(5)}$ & $\mathrm{C} / \mathrm{O}$ \\
\hline & \multicolumn{3}{|c|}{ PARENT CNFs } & 127 & $33(26 \%)$ & $0.147(20 \%)$ & 0.590 & 10.8 & 92.0 & 5.5 & 2.5 & 37.3 \\
\hline $1 / 1$ & 850 & 500 & 90 & 182 & $92(50 \%)$ & $0.373(47 \%)$ & 0.415 & 10.7 & 90.3 & 5.0 & 4.7 & 19.0 \\
\hline $2 / 1$ & 850 & 500 & 72 & 224 & $117(52 \%)$ & $0.918(68 \%)$ & 0.421 & 10.3 & 88.5 & 4.7 & 6.8 & 12.9 \\
\hline $3 / 1$ & 850 & 500 & 67 & 246 & $133(54 \%)$ & $1.014(70 \%)$ & 0.436 & 10.0 & 87.5 & 4.7 & 7.9 & 11.1 \\
\hline $4 / 1$ & 850 & 500 & 63 & 290 & $171(59 \%)$ & $1.706(80 \%)$ & 0.308 & 9.3 & 83.4 & 5.0 & 11.6 & 7.2 \\
\hline $5 / 1$ & 850 & 500 & 60 & 268 & $131(49 \%)$ & $1.069(69 \%)$ & 0.484 & 9.8 & 86.0 & 5.3 & 8.7 & 9.9 \\
\hline $4 / 1$ & 700 & 500 & 95 & 160 & $58(36 \%)$ & $0.386(45 \%)$ & 0.461 & 10.7 & 91.8 & 5.4 & 2.7 & 33.9 \\
\hline $4 / 1$ & 800 & 500 & 67 & 241 & $133(55 \%)$ & $0.943(72 \%)$ & 0.368 & 10.1 & 88.0 & 4.8 & 7.2 & 12.3 \\
\hline $4 / 1$ & 850 & 500 & 63 & 290 & $171(59 \%)$ & $1.706(80 \%)$ & 0.308 & 9.3 & 83.4 & 5.0 & 11.6 & 7.2 \\
\hline $4 / 1$ & 900 & 500 & 56 & 334 & $194(58 \%)$ & $1.515(74 \%)$ & 0.535 & 8.8 & 80.3 & 5.2 & 14.5 & 5.5 \\
\hline $4 / 1$ & 900 & 150 & 68 & 247 & $145(59 \%)$ & $0.847(73 \%)$ & 0.401 & 10.1 & 87.5 & 4.7 & 7.8 & 11.3 \\
\hline $4 / 1$ & 900 & 500 & 56 & 334 & $194(58 \%)$ & $1.515(83 \%)$ & 0.535 & 8.8 & 80.3 & 5.2 & 14.5 & 5.5 \\
\hline $4 / 1$ & 900 & 700 & 55 & 338 & $198(59 \%)$ & $1.720(77 \%)$ & 0.506 & 8.7 & 80.0 & 5.0 & 15.0 & 5.3 \\
\hline $4 / 1$ & 900 & 850 & 54 & 383 & $235(61 \%)$ & $2.835(87 \%)$ & 0.400 & 8.6 & 79.8 & 4.8 & 15.4 & 5.2 \\
\hline $4 / 1$ & 900 & 1000 & 55 & 342 & $215(63 \%)$ & $1.801(89 \%)$ & 0.215 & 8.7 & 80.1 & 5.1 & 14.8 & 5.4 \\
\hline
\end{tabular}

${ }^{(1)}$ In brackets: percentage of micropore area with respect to the total surface area. ${ }^{(2)}$ Cumulative micropore volume obtained using the Horvath-Kawazoe method. In brackets: percentage of micropore volume respect to the total pore volume. ${ }^{(3)}$ Cumulative mesopore volume obtained using the BJH method. ${ }^{(4)} \mathrm{npg}=\mathrm{Lc} / \mathrm{d}_{002}^{(5)} \mathrm{O}_{\text {diff: }}$ the oxygen is assessed by difference up to $100 \%$.

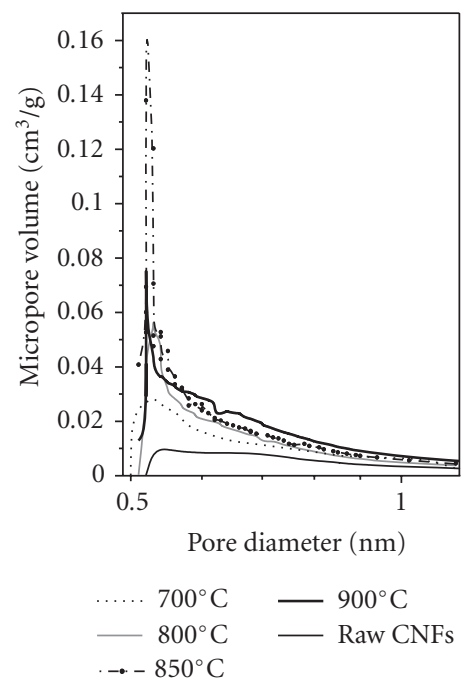

(a)

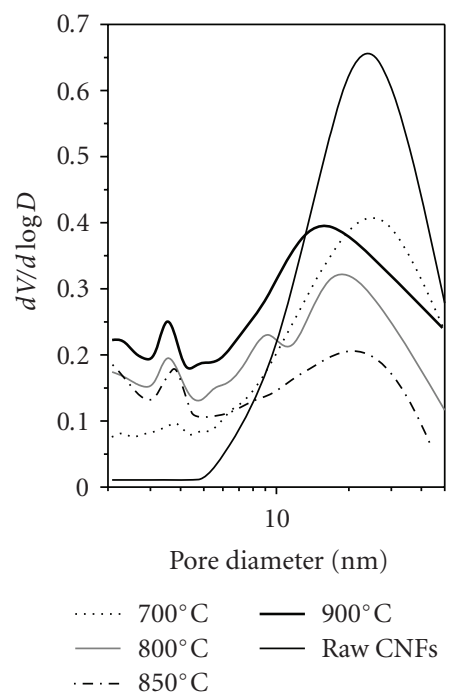

(b)

FIGURE 2: (a) Micropore (Horward-Kawazoe method) and (b) mesopore (BJH method) size distribution as a function of the activation temperature.

Finally, He flow rates in the range $150-850 \mathrm{~mL} \mathrm{~min}^{-1}$ promoted principally the ultramicropore development; nevertheless, a further increase in the He flow rate until $1000 \mathrm{~mL} \mathrm{~min}^{-1}$ was such enough to deteriorate the pore development.

Summarizing, $\mathrm{RbOH} / \mathrm{CNFs}$ ratio, activation temperature and He flow rate are very important parameters in the porosity control of CNFs. To explain the obtained results, it is necessary to take into consideration that during the activation reaction, $\mathrm{Rb}$ is formed. Although this metal can be removed from the carbon matrix by evaporation (boiling point of $\mathrm{Rb}: 688^{\circ} \mathrm{C}$ ), a proportion of it can also be intercalated, which produces the pore opening of the parent $\mathrm{CNFs}$, since some graphitic structures are destroyed and micropores and sometimes mesopores are generated [11]. Obviously, a strong interaction between the $\mathrm{Rb}$ and CNFs 


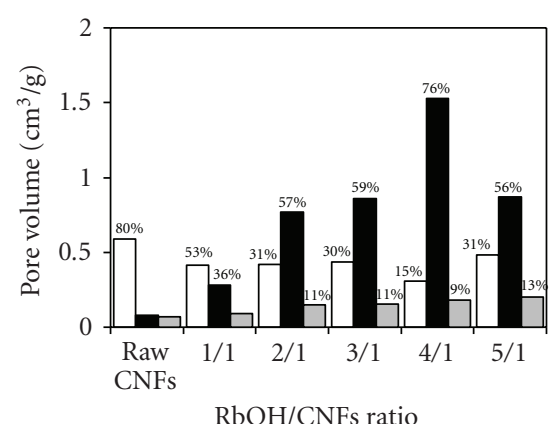

Mesopore volume

- Ultramicropore volume

$\square$ Supermicropore volume

(a)

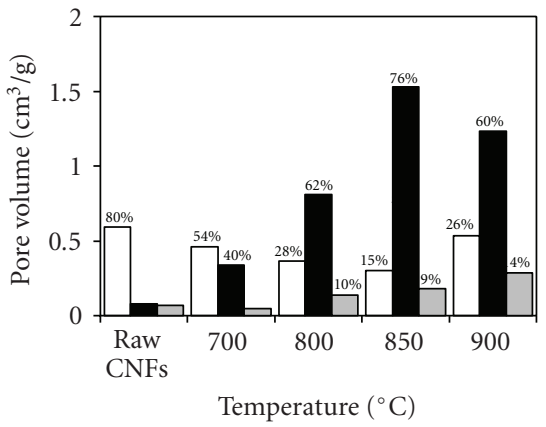

$\square$ Mesopore volume

- Ultramicropore volume

口 Supermicropore volume

(b)

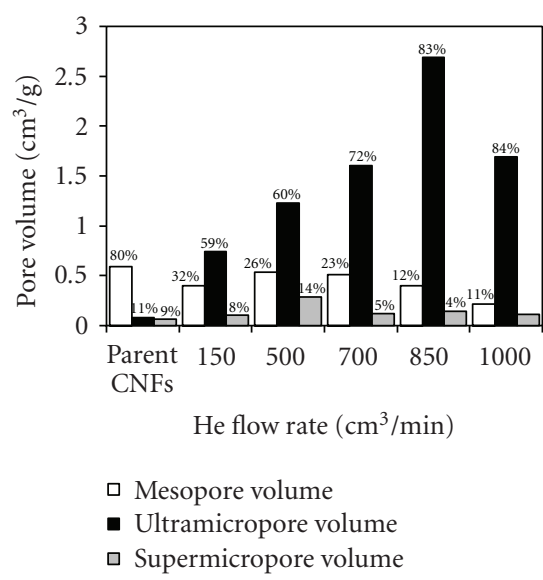

(c)

Figure 3: Proportion of ultramicropores $(<0.7 \mathrm{~nm})$, supermicropores $(0.7-2 \mathrm{~nm})$, and mesopores $(2-50 \mathrm{~nm})$ at different $(\mathrm{a}) \mathrm{RbOH} / \mathrm{CNFs}$ ratio, (b) activation temperatures, and (c) He flow rates. (Activation conditions are showen in Table 1.)

will produce the generation of new mesopores while a mild interaction will induce only the generation of micropores (in part due to the original CNFs mesopores destruction). Thus, the $\mathrm{Rb}-\mathrm{CNF}$ interaction strength can be easily improved with an increase in the $\mathrm{RbOH} / \mathrm{CNF}$ ratio and temperature, so that an important CNFs pore structure development (including both micropores and sometimes also mesopores) took place. Nevertheless, when the $\mathrm{RbOH} / \mathrm{CNF}$ ratio and reaction temperature exceed a determinate limit, no new micropores are generated and even they can disappear by its strong interaction with the activating agent $(\mathrm{Rb})$ generating some new mesopores (reforming reactions could occur in the activated CNFs, widening some micropores to larger mesopores and so, decreasing the surface area and micropore volume but, increasing the mesopore volume [12]). Respect to the He flow rate, it is necessary to have into account the removal of gases evolved during the activation process. Fast removal of gases such as $\mathrm{CO}, \mathrm{CO}_{2}, \mathrm{H}_{2}, \mathrm{Rb}$ favours the porosity development and it occurs at higher flow rates values, because the equilibrium of the principal reaction $(6$ $\left.\mathrm{RbOH}+2 \mathrm{C} \leftrightarrow 2 \mathrm{Rb}+3 \mathrm{H}_{2}+2 \mathrm{Rb}_{2} \mathrm{CO}_{3}\right)$ is displaced to the production of further $\mathrm{Rb}$, increasing the degree of reaction between $\mathrm{CNF}$ and $\mathrm{RbOH}$. Nevertheless, $\mathrm{H}_{2} \mathrm{O}$ is also formed during pyrolysis reactions (e.g: $4 \mathrm{RbOH}+\mathrm{C} \leftrightarrow 4 \mathrm{Rb}+\mathrm{CO}_{2}$ $\left.+2 \mathrm{H}_{2} \mathrm{O} ; 4 \mathrm{RbOH}+2 \mathrm{CO}_{2} \leftrightarrow 2 \mathrm{Rb}_{2} \mathrm{CO}_{3}+2 \mathrm{H}_{2} \mathrm{O}\right)$ and its removal of the reaction place is against the activation due to $\mathrm{H}_{2} \mathrm{O}_{\mathrm{v}}$ has the ability of penetrate the solid material and to help desorption and efficient removal of the volatile products from it [13]. Therefore, a balance between these two removal processes exists; a He flow rate too high could remove of the reaction place a too high amount of $\mathrm{H}_{2} \mathrm{O}$ in detrimental of the porous properties of CNFs, and a small He flow rate probably do not removal $\mathrm{CO}, \mathrm{CO}_{2} \ldots$ enough, also in detrimental of the activation.

The graphitization degree can be quantified using the average interlayer spacing $\left(\mathrm{d}_{002}\right)$ and the average stacking height of carbon planes (Lc), which are expressed in Table 1 as the mean number of grapheme planes in the crystallites (npg). npg values varied in the range [10.8 (raw CNFs)-8.6] being lower when higher the activation degree was. Anyway, npg values were pretty high if compared with those reported for conventional activated carbon or activated carbon fibers, indicating that the graphitic nature of the raw CNFs remains present in the activated samples [7].

Finally, according to the mass balance of reagents, raw CNFs were composed of carbon, hydrogen and oxygen, in a relative molar proportion of $92 \%, 5.5 \%$ and $2.5 \%$. After the activation process, carbon content decreased, hydrogen content was approximately kept constant, whereas oxygen content increased (C/O ratio drastically decreased in CNFs with the activation degree).

\section{Conclusions}

Depending on the final application of the activated materials, it is possible to control their pore structure by choosing the suitable activation conditions. The best results of activated CNFs with larger specific surface area can be achieved using the following optimized factors: $\mathrm{RbOH} / \mathrm{CNF}$ ratio $=4 / 1$, activation temperature $=900^{\circ} \mathrm{C}$, and a He flow rate $=$ $850 \mathrm{~mL} / \mathrm{min}$.

\section{References}

[1] R. T. K. Baker, K. Laubernds, A. Wootsch, and Z. Paal, "Pt/graphite nanofiber catalyst in n-hexane test reaction," Journal of Catalysis, vol. 193, no. 1, pp. 165-167, 2000.

[2] K. Lozano and E. V. Barrera, "Nanofiber-reinforced thermoplastic composites. I. Thermoanalytical and mechanical analyses," Journal of Applied Polymer Science, vol. 79, no. 1, pp. 125-133, 2001.

[3] C. A. Bessel, K. Laubernds, N. M. Rodriguez, and R. T. K. Baker, "Graphite nanofibers as an electrode for fuel cell applications," Journal of Physical Chemistry B, vol. 105, no. 6, pp. 1115-1118, 2001. 
[4] C. Park and R. T. K. Baker, "Carbon deposition on iron-nickel during interaction with ethylene-carbon monoxide-hydrogen mixtures," Journal of Catalysis, vol. 190, no. 1, pp. 104-117, 2000.

[5] M. Marella and M. Tomaselli, "Synthesis of carbon nanofibers and measurements of hydrogen storage," Carbon, vol. 44, no. 8, pp. 1404-1413, 2006.

[6] S. Mitani, S.-I. Lee, K. Saito, S.-H. Yoon, Y. Korai, and I. Mochida, "Activation of coal tar derived needle coke with $\mathrm{K}_{2} \mathrm{CO}_{3}$ into an active carbon of low surface area and its performance as unique electrode of electric double-layer capacitor," Carbon, vol. 43, no. 14, pp. 2960-2967, 2005.

[7] D. Luxembourg, X. Py, A. Didion, R. Gadiou, C. Vix-Guterl, and G. Flamant, "Chemical activations of herringbone-type nanofibers," Microporous and Mesoporous Materials, vol. 98, no. 1-3, pp. 123-131, 2007.

[8] J. A. Maciá-Agulló, B. C. Moore, D. Cazorla-Amoros, and A. Linares-Solano, "Influence of carbon fibres crystallinities on their chemical activation by $\mathrm{KOH}$ and $\mathrm{NaOH}$," Microporous and Mesoporous Materials, vol. 101, no. 3, pp. 397-405, 2007.

[9] V. Jiménez, P. Sánchez, A. de Lucas, J. L. Valverde, and A. Romero, "Influence of the nature of the metal hydroxide in the porosity development of carbon nanofibers," Journal of Colloid and Interface Science, vol. 336, no. 1, pp. 226-234, 2009.

[10] V. Jiménez, P. Sánchez, J. L. Valverde, and A. Romero, "Influence of the activating agent and the inert gas (type and flow) used in an activation process for the porosity development of carbon nanofibers," Journal of Colloid and Interface Science, vol. 336, no. 2, pp. 712-722, 2009.

[11] J. J. Niu and J. N. Wang, "Effect of temperature on chemical activation of carbon nanotubes," Solid State Sciences, vol. 10, no. 9, pp. 1189-1193, 2008.

[12] Q. Jiang and Y. Zhao, "Effects of activation conditions on BET specific surface area of activated carbon nanotubes," Microporous and Mesoporous Materials, vol. 76, no. 1-3, pp. 215-219, 2004.

[13] V. Minkova, M. Razvigorova, E. Bjornbom, R. Zanzi, T. Budinova, and N. Petrov, "Effect of water vapour and biomass nature on the yield and quality of the pyrolysis products from biomass," Fuel Processing Technology, vol. 70, no. 1, pp. 53-61, 2001. 

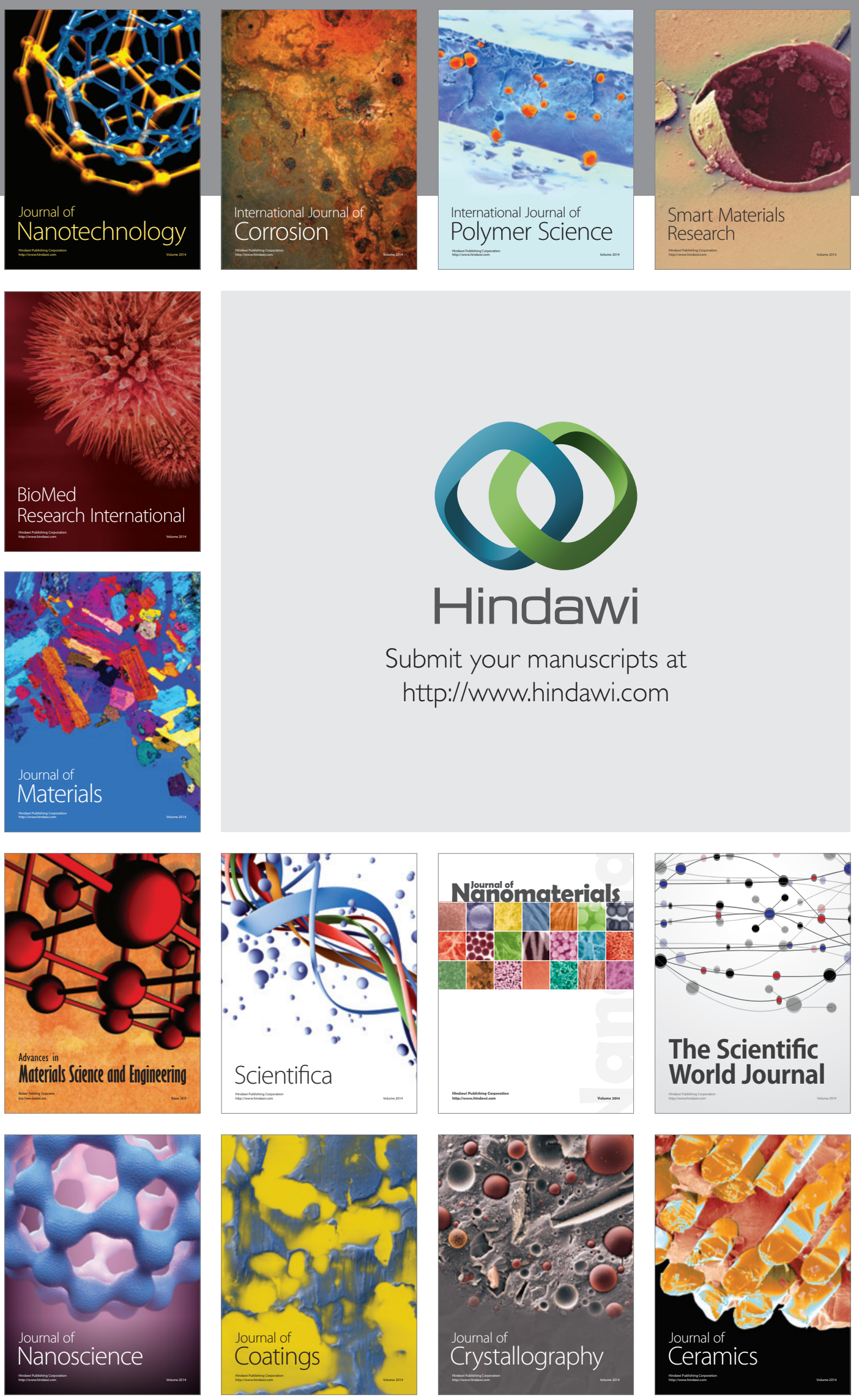

The Scientific World Journal

Submit your manuscripts at

http://www.hindawi.com

\section{World Journal}

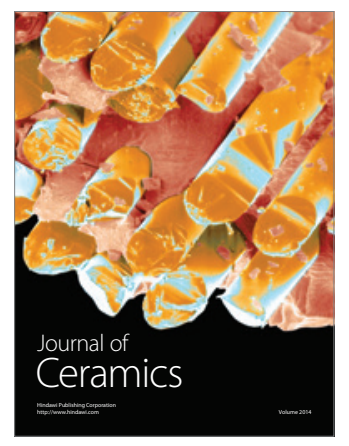

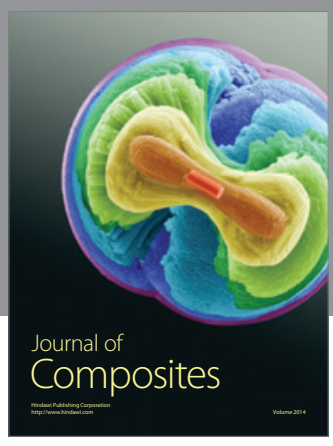
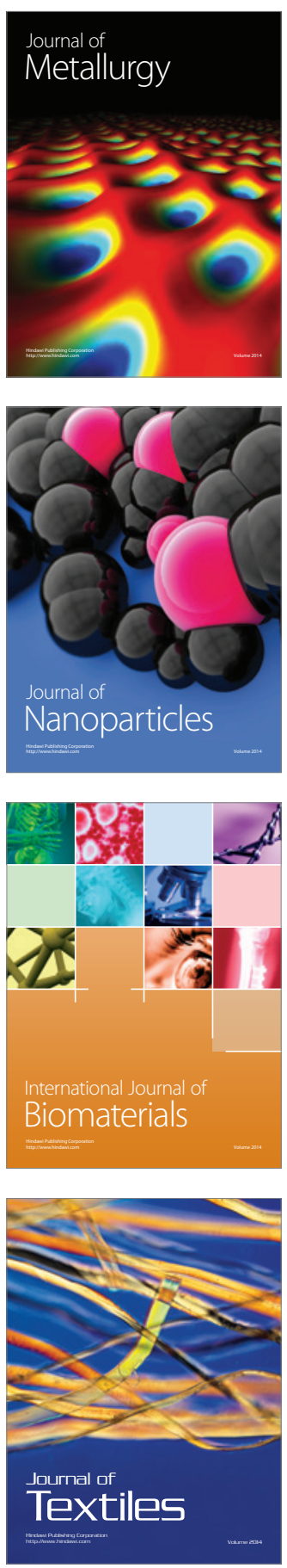